\title{
Genetic testing for maturity onset diabetes of the young in childhood hyperglycaemia
}

\author{
K A Matyka, F Beards, M Appleton, S Ellard, A Hattersley, D B Dunger
}

\begin{abstract}
Mild hyperglycaemia is a common finding during minor illness in children. The differential diagnosis includes maturity onset diabetes of the young (MODY), which can be a difficult diagnosis to make clinically. As most genes resulting in MODY have been identified, it is possible to make a firm diagnosis using mutation detection. A case is reported of a 4 year old girl in whom a diagnosis of MODY2 was established by the finding of a heterozygous missense mutation in exon 7 of the glucokinase gene, resulting in the substitution at codon 259 of alanine by threonine (A259T). Observations from other glucokinase families suggest that hyperglycaemia in this child is likely to be stable and will not require intensive medical follow up, whereas other forms of MODY (1, 3, and 4) might carry a different prognosis.

(Arch Dis Child 1998;78:552-554)
\end{abstract}

Keywords: maturity onset diabetes of the young; hyperglycaemia; DNA sequencing; mutation

Incidental hyperglycaemia is a common finding in young children with intercurrent illness. A study from the Children's Hospital Medical Center, Boston in 1993 found that transient hyperglycaemia (defined as a random blood glucose of $>8 \mathrm{mmol} / \mathrm{l}$ ) occurred in $0.46 \%$ of children seen in the emergency department. ${ }^{1}$ The appropriate management of these children remains unclear. Incipient insulin dependent diabetes mellitus remains the most likely diagnosis and intensive follow up is usually recom- mended, but the differential diagnosis includes endocrine disorders, genetic syndromes, and drugs (fig 1). Maturity onset diabetes of the young, MODY, is an uncommon condition, difficult to diagnose clinically, yet an important diagnosis to make as it has both therapeutic and genetic implications.

We present a patient in whom making a firm diagnosis of MODY with molecular genetic testing has dramatically altered the approach to management.

\section{Case presentation}

A 4 year old girl, who previously had been well, presented with a short history of dysuria and frequency and was found to have heavy glycosuria, but no ketonuria. Subsequently, urine was found to be negative on bacterial culture. Her height was $1.03 \mathrm{~m}$ (75th centile), her weight was $15.4 \mathrm{~kg}$ ( 25 th centile), and her body mass index was $14.5 \mathrm{~kg} / \mathrm{m}^{2}$. General examination was unremarkable. Fasting blood glucose was $6.5 \mathrm{mmol} / \mathrm{l}$ (normal range, 3-5.5 mmol/l). $\mathrm{HbA} 1 \mathrm{c}$ was $5.9 \%$ (normal range, 4.3-6.1\%) and islet cell antibodies were negative. A standard oral glucose tolerance test was performed $(1.75 \mathrm{~g} / \mathrm{kg}$ of glucose, up to a maximum of $75 \mathrm{~g}$ ). On this occasion, the fasting blood glucose was $5.4 \mathrm{mmol} / \mathrm{l}$, with a two hour value in the diabetic range, according to the American Diabetes Association (ADA) revised criteria, ${ }^{2}$ at $11.2 \mathrm{mmol} / 1$ (table 1 ). She was an only child at presentation.

Her mother developed gestational diabetes during her first pregnancy and had a raised fasting plasma glucose value of $7.3 \mathrm{mmol} / 1$, in the diabetic range by ADA criteria, with a two
Department of

Paediatrics, University of Oxford, John Radcliffe Hospital, Oxford OX3 9DU, UK K A Matyka

D B Dunger

Department of Vascular Medicine and Diabetes Research, Postgraduate Medical

School, Exeter

EX2 5AX, UK

F Beards

M Appleton

$S$ Ellard

A Hattersley

Correspondence to: Dr Dunger.

email:david.dunger@ paediatrics.oxford.ac.uk

Accepted 24 November 1997

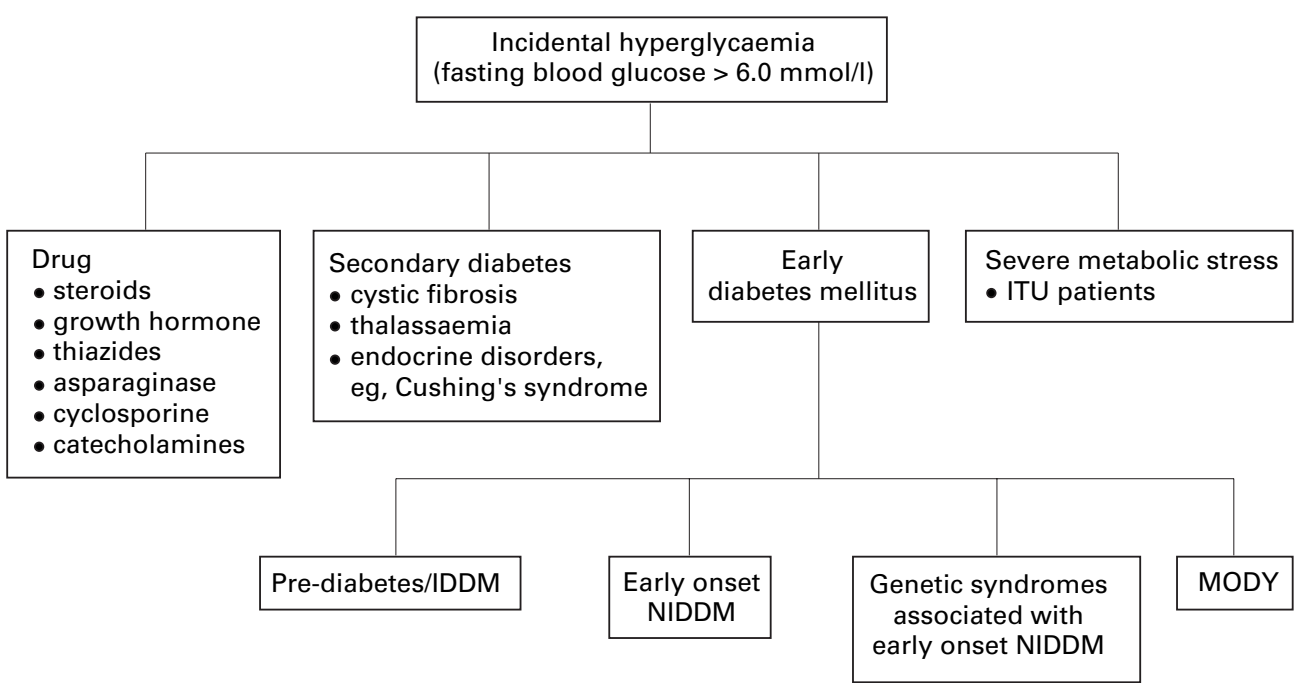

Figure 1 Differential diagnosis of incidental hyperglycaemia. IDDM, insulin dependent diabetes mellitus; NIDDM, non-insulin dependent diabetes mellitus. 
Table 1 Results of oral glucose tolerance test

\begin{tabular}{cccl}
\hline $\begin{array}{l}\text { Time } \\
\text { (minutes) }\end{array}$ & $\begin{array}{l}\text { Glucose } \\
\text { (mmolll) }\end{array}$ & $\begin{array}{l}\text { Insulin } \\
(m U / l)\end{array}$ & $\begin{array}{l}\text { C peptide } \\
\text { (nmol/l) }\end{array}$ \\
\hline 0 & 5.4 & 3.1 & 0.29 \\
30 & 10.0 & 15.3 & 1.03 \\
60 & 12.5 & 17.9 & 1.35 \\
90 & 12.7 & 20.8 & 1.39 \\
120 & 11.2 & 23.7 & 1.59 \\
\hline
\end{tabular}

hour value of $7.3 \mathrm{mmol} / \mathrm{l}$ after a $75 \mathrm{~g}$ oral glucose tolerance test. Subsequently, she developed gestational diabetes with her second pregnancy, requiring insulin therapy, which was discontinued after delivery. The mother's maternal grandfather was thought to have had non-insulin dependent diabetes mellitus, but details were lacking.

\section{Pedigree analysis}

The patient and five other members of the immediate family were screened as shown in the diagram of the family tree (fig 2). Blood was taken for fasting plasma glucose, urea and electrolytes, plasma lipids, and HbAlc; lymphocytes were also obtained for DNA extraction.

The mother had a raised $\mathrm{HbA} 1 \mathrm{c}$ of $6.7 \%$. The maternal grandmother had a raised, but not diabetic, fasting glucose value of $5.8 \mathrm{mmol} / 1$, more than two standard deviations above the normal population mean. The remainder of the family tested had normal biochemical findings.

\section{Genetic testing}

The proband's DNA was extracted and all 12 exons of the glucokinase gene were sequenced using an automatic sequencer as described previously (Beards et al, unpublished data, 1997). In exon 7, a heterozygous missense mutation was detected at codon 259 , which results in the replacement of alanine (GCC) with threonine (ACC). This mutation, designated A259T, was also found by direct

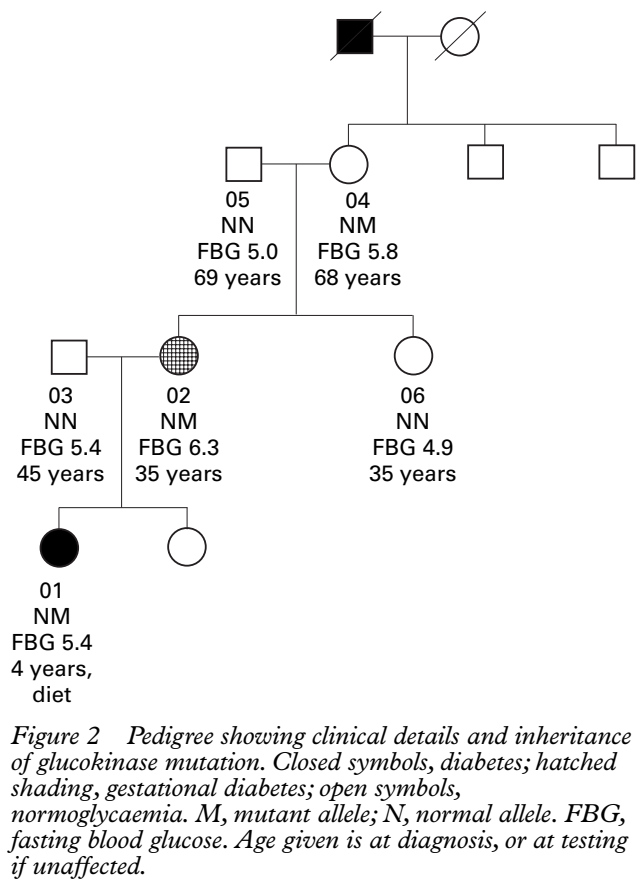

\section{Key messages}

- Maturity onset diabetes of the young is an important diagnosis to consider in a child with incidental hyperglycaemia.

- If considered, parents' fasting blood glucose should be measured. If raised, molecular genetic testing may be useful.

- Molecular genetic testing has defined four different phenotypes of MODY with different clinical courses and prognoses.

- MODY2, resulting in defects of the glucokinase gene, carries a good prognosis.

sequencing in the proband's mother and maternal grandmother. Therefore, the diagnosis of MODY2, resulting from a mutation in the glucokinase gene, was made.

\section{Discussion}

Maturity onset diabetes of the young is an uncommon condition first identified by Tattersall in $1974 .{ }^{3}$ It is characterised by presentation of non-insulin dependent diabetes mellitus (shown by the absence of insulin treatment five years after diagnosis or significant $\mathrm{C}$ peptide levels in a patient on insulin treatment) before 25 years of age in at least one, but ideally two, family members, and autosomal dominant inheritance. ${ }^{4}$ In the past five years, the clinical heterogeneity has been explained, at least in part, by the genetic heterogeneity. There are four specific subgroups of MODY characterised by mutations of known genes: MODY1, hepatic nuclear factor 4 alpha $(\mathrm{HNF} 4 \alpha)^{5}$; MODY2, glucokinase ${ }^{6}$; MODY3, hepatic nuclear factor 1 alpha $(\mathrm{HNF} 1 \alpha)^{7}{ }^{8}$; and MODY 4 , insulin promoter factor 1 (IPF-1). ${ }^{9}$ The types of MODY where the genes are known account for $80 \%$ of all patients in the UK and France and have discrete clinical courses.

In our patient, the diagnosis of MODY2 was made by the finding of a mutation in exon 7 of the glucokinase gene. This mutation, which results in a change from the non-polar amino acid alanine to an uncharged polar amino acid threonine, segregated with mild hyperglycaemia in the pedigree and was not found in 50 control chromosomes (Beards et al, unpublished data, 1997). In addition, it is known to be in a part of the glucokinase gene that encodes the glucose binding site. All these features make it highly likely to be a pathogenic mutation. This allowed us to make a firm diagnosis of MODY2. The clinical characteristics are consistent with this case: patients show early onset of mild fasting hyperglycaemia, which remains relatively stable throughout life, is asymptomatic, and microvascular complications are rare. ${ }^{40}$ This fasting hyperglycaemia is often not detected unless specifically screened for. Frequently, patients are diagnosed during pregnancy and usually require temporary insulin treatment, ${ }^{4}$ as in the case of our patient's mother. Over $50 \%$ of cases do not reach ADA 
criteria for diabetes, but the finding of an elevated fasting blood glucose is consistent, ${ }^{46}$ and this was shown in all three family members with the mutation.

In the UK, the most common form of MODY is MODY3, which results from mutations in the HNF1 $\alpha$ gene. ${ }^{8}$ This has a different clinical course from patients with glucokinase mutations in that, typically, subjects are born with normal glucose tolerance and normal fasting glucose but develop symptomatic diabetes in adolescence or early adulthood. These patients show a progressive course with increasing treatment requirements with age and, unlike patients with glucokinase mutations, are at risk of microvascular complications, particularly retinopathy. ${ }^{4}$ The establishment of a diagnosis of MODY3 means that it is important to continue to follow the individual closely to ensure near normoglycaemia to avoid microvascular complications.

MODY1, resulting from a mutation in the HNF $4 \alpha$ gene, has only been described in one large North American pedigree. ${ }^{5}$ They have progressive deterioration of $\beta$ cell function and both micro- and macrovascular complications are common. MODY4 has been described in a single pedigree, in whom the clinical course appears to be milder, with most affected individuals being on diet or oral hypoglycaemic agents only. ${ }^{9}$

Maturity onset diabetes of the young should always be considered as a possible diagnosis in children who present with incidental hyperglycaemia and have a parental history of noninsulin dependent diabetes, glucose intolerance, or gestational diabetes. If MODY is considered, fasting plasma glucose should be measured in both parents as, if raised above $5.5 \mathrm{mmol} / 1$ in either parent, molecular genetic testing could be useful. In our patient, failure to make the diagnosis would have resulted in repeated assessments of glucose tolerance. Now, with the diagnosis of MODY2, the spectre of insulin dependent diabetes mellitus has been removed and the family have been reassured as to the likely long term outcome. We feel that molecular genetic testing for MODY can be a useful diagnostic test in children with mild hyperglycaemia and a family history of non-insulin dependent diabetes mellitus or gestational diabetes.

Funding for the molecular genetic work carried out at Exeter University was provided by the Northcott Trust, Exeter University was provided by the Northcott Trust, Exeter University, the British Diabetic Association, and the Medical
Research Council. KM has a British Diabetic Association training fellowship.

1 Herskowitz-Dumont R, Wolfsdorf JI, Jackson RA, Eisenbarth GS. Distinction between transient hyperglycaemia barth GS. Distinction between transient hyperglycaemia a prospective study of incidence and prognostic factors. $\mathcal{F}$ Pediatr 1993;123:347-54.

2 The Expert Committee on the Diagnosis and Classification of Diabetes Mellitus. Report of the expert committee on the diagnosis and classification of diabetes mellitus. Diabetes Care 1997;20:1183-97.

3 Tattersall RB. Mild familial diabetes with dominant inheritance. $Q \mathcal{F}$ Med 1974;43:339-57.

4 Hattersley AT. Maturity-onset diabetes of the young. Bailliere's Clin Paediatr 1996;4:663-80.

5 Yamagata K, Furuta $\mathrm{H}$, Oda N, et al. Mutations in the hepatocyte nuclear factor 4 alpha gene in maturity-onset

diabetes of the young (MODY1). Nature 1996;384:458-60. emia due to mutations in glucokinase. Definition of a subemia due to mutations in glucokinase. Definition of a s
type of diabetes mellitus. N Engl F Med 1993;328:697.

7 Yamagata K, Oda N, Kaisaki PJ, et al. Mutations in the Yamagata K, Oda N, Kaisaki PJ, et al. Mutations in the hepatic nuclear factor alpha gene in maturity-onset
diabetes of the young (MODY3). Nature 1996;384:455-8.

8 Frayling T, Bulman MP, Ellard S, et al. Mutations in the hepatocyte nuclear factor 1 alpha gene are a common cause of maturity-onset diabetes of the young in the United Kingdom. Diabetes 1997;46:720-5.

9 Stoffers DA, Ferrer J, Clarke WL, Habener JF. Early-onset type-II diabetes mellitus (MODY 4) linked to IPF-1. Nat Genet 1997;17:138-9.

10 Velho $\mathrm{G}$, Blanche $\mathrm{H}$, Vaxillaire $\mathrm{M}$, et al. Identification of 14 new glucokinase mutations and description of the clinical profile of 42 MODY-2 families. Diabetologia 1997;40:217- 